\title{
Synthesis and properties of porous SiC ceramics
}

V. S. Kiselov, P. M. Lytvyn, V. O. Yukhymchuk, A. E. Belyaev, and S. A. Vitusevich

Citation: Journal of Applied Physics 107, 093510 (2010);

View online: https://doi.org/10.1063/1.3407565

View Table of Contents: http://aip.scitation.org/toc/jap/107/9

Published by the American Institute of Physics

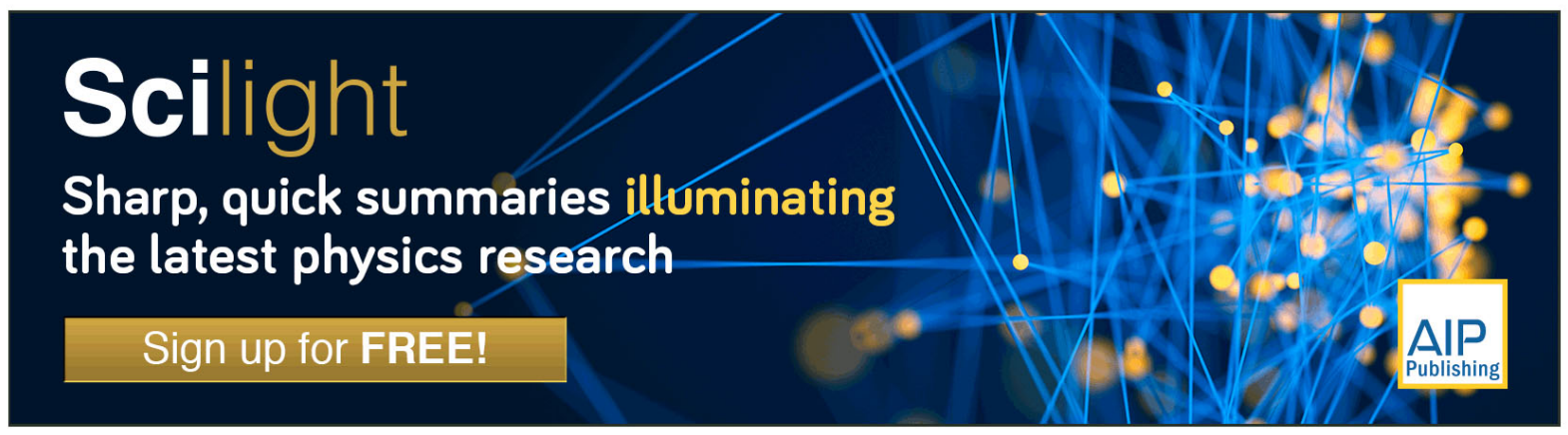




\title{
Synthesis and properties of porous SiC ceramics
}

\author{
V. S. Kiselov, ${ }^{1}$ P. M. Lytvyn, ${ }^{1}$ V. O. Yukhymchuk, ${ }^{1}$ A. E. Belyaev,${ }^{1}$ and S. A. Vitusevich ${ }^{2, a)}$ \\ ${ }^{1}$ V. Lashkaryov Institute of Semiconductor Physics, NAS of Ukraine, Nauky 41, 03028 Kyiv, Ukraine \\ ${ }^{2}$ Institute of Bio- and Nanosystems and Jülich-Aachen Research Alliance for Future Information Technology \\ (JARA-FIT), Forschungszentrum Jülich, 52425 Juelich, Germany
}

(Received 27 August 2009; accepted 25 March 2010; published online 4 May 2010)

\begin{abstract}
Porous silicon carbide $(\mathrm{SiC})$ ceramics are produced using carbon matrices derived from natural wood. Such material is especially promising as it is environmentally friendly with attractive physical properties, including a high level of biocompatibility, chemical inertness, and mechanical strength. We have developed a forced impregnation process with further synthesis of $\mathrm{SiC}$ using natural wood as well as a variety of industrial carbon materials and compared the properties of these ceramics. The structure and composition of the materials obtained were investigated by Raman scattering spectroscopy. The hardness of the samples was estimated using the Vickers technique. It was shown that the phase composition and mechanical properties of synthesized $\mathrm{SiC}$ ceramics can be effectively controlled by the initial Si contents and temperature of the synthesis process. A large variety of options are demonstrated for materials development taking into account an optimal porosity selection for various practical applications. (C) 2010 American Institute of Physics. [doi:10.1063/1.3407565]
\end{abstract}

\section{INTRODUCTION}

Silicon carbide $(\mathrm{SiC})$ ceramics have a great potential for a number of industrial applications due to their high mechanical strength, low thermal expansion coefficient, low value of relative density, high chemical inertness, oxidation, and corrosion resistance. Recently, bulk porous $\mathrm{SiC}$ ceramics have attracted increasing interest in medical applications as materials with high biocompatibility ${ }^{1,2}$ for the production of orthopedic and dental implants. Indeed, ceramic materials possess better biocompatibility compared to metals and polymers, which allows them to be used as implants in medicine and also as functional materials in biotechnology and genetic engineering. In a number of papers it has been reported that $\mathrm{SiC}$ ceramics can be used as a coating material for stents to improve their hemocompatibility ${ }^{3,4}$ and as titanium-based total hip replacement implants. ${ }^{5}$ Biomorphic SiC ceramics coated with bioactive glass have been proposed as a promising material for dental and orthopedic implants. ${ }^{6}$ Experiments in vitro and in vivo ${ }^{7}$ demonstrate excellent biocompatibility of the $\mathrm{SiC}$ ceramic fabricated from wood due to the inter-related hierarchical porous structure of such material. Porous $\mathrm{SiC}$ has been introduced as a potential candidate for in vivo membrane applications. ${ }^{8}$ Attention has been focused on the suitability of $\mathrm{SiC}$ ceramics with pore sizes of tens of nanometers as a membrane material for implantable microdevices in biomedical applications.

Porous ceramics/composites derived from wood (biomorphic ceramics), sawdust and paper have received particular attention in the past decade. ${ }^{9-14} \mathrm{Bio}-\mathrm{SiC}$ and $\mathrm{SiC}$ microfiber rods are most promising for medical applications, especially for orthopedic implants, composite $\mathrm{SiC}-\mathrm{C}$ electrodes, etc. Synthesized microporous $\mathrm{SiC}$ ceramics can be

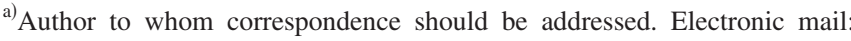
s.vitusevich@fz-juelich.de.On leave from Institute of Semiconductor Physics, NASU, Kiev, Ukraine.
}

used for filtering aggressive liquids and gases. SiC ceramics produced from carbon foam, fabric and felt are promising for applications as thermal isolation in furnaces due to their low thermal conductivity and high chemical and fire resistance. In addition, the ceramics can be used in nuclear and thermonuclear reactors as a covering material due to their low atomic weight and high neutron absorption by carbon.

Wood is characterized by a hierarchical anatomy, complex architecture, and open uniaxial anisotropic porosity containing a variety of cellular/porous features. Diameters of channels range from 4 to $150 \mu \mathrm{m}$ in these materials. New types of $\mathrm{SiC}$ ceramics have been produced recently using this technique $^{9-11}$ via a reactive impregnation of the natural carbon precursors from wood with molten $\mathrm{Si}$. The main advantages of this technique are low cost, high productivity, and near-net-shape fabrication. These biomorphic ceramics show a wide variety of microstructures, densities, and hardness, which are determined by the type of wood. Other techniques have also been proposed for bioceramic fabrication including reactive impregnation with $\mathrm{SiO}$ vapor, chemical vapor impregnation reaction, ${ }^{1,12,13}$ etc.

The key feature of carbon templates for $\mathrm{SiC}$ ceramics is the open type of porosity that provides the possibility of changing the material properties by the impregnation process using vapor or liquid silicon. Therefore, materials of various porosity fabricated from pyrolyzed wood can be used as carbon matrices for producing $\mathrm{SiC}$ ceramics via silicon impregnation process. This technique allows porous $\mathrm{SiC}$ materials to be produced with different properties i.e., porosity, density, and hardness. On the other hand, systematic investigations of the impregnation process, a detailed understanding of $\mathrm{SiC}$ ceramics synthesis and the influence of synthesis conditions on the physical properties of the final product are need to produce materials with predefined properties.

We previously examined the effect of the infiltration method with liquid or vapor silicon on the microstructure of 
wood-based biomorphous SiC (Ref. 14) and investigated the thermoelectric properties of such ceramics. ${ }^{15}$ The aim of the work reported here was to study the influence of the technological factors, such as temperature of the processes of impregnation/syntheses, temperature, and duration of the evaporation process of excess silicon as well as the influence of starting Si content on the physical parameters of the ceramics. The forced impregnation process (FIP) was applied to achieve a uniform silicon distribution over whole volumes of matrices because it is difficult to obtain this with the spontaneous infiltration process.

\section{EXPERIMENTAL DETAILS}

\section{A. Fabrication process of the carbon matrices}

Two different kind materials such as: natural wood and industrially produced carbon were used as the carbon matrices. In the first case, a well-known process flow is used ${ }^{9-11}$ in the atmosphere of inert gas $(\mathrm{N}$ or $\mathrm{Ar})$ at $900{ }^{\circ} \mathrm{C}$. Different types of natural hardwoods widespread in Ukraine (dicotyledonous angiosperms) with diffusive porous patterns were selected. In particular, Persian walnut (Juglans regia), beech (Fagus sylvatica), alder (Alnus glutinosa), European hornbeam (Carpinus betulus), and pear tree (Pyrus domestica) were investigated. In the second case, we used carbon matrices of various forms made from industrially produced carbon fibers, foils, filaments, fabrics, felts, carbon foam, and their combinations. Thus, rodlike products were made from bunches of carbon fibers. The measured diameter of the single fiber was in the range of 5-7 $\mu \mathrm{m}$. Bunches of fibers were stacked and fixed by carbon filaments and consequently impregnated by phenol-formaldehyde resin and dried. Products from carbon felt, fabric, and foil were made by cutting pieces of the required shape and sewing them together with carbon filaments and impregnating them with phenolformaldehyde resin. Therefore, products of complex shapes can be made using combinations of fabric, felt, and foil. Carbon foam was used to form the required shapes of different geometry. It should be noted that the special feature of this material is its closed porosity. Impregnation and $\mathrm{SiC}$ synthesis take place in the superficial layer only.

\section{B. The FIP by Si and syntheses of the SiC}

The REDMET-30 industrial furnace; was used for thermal operations. Carbon matrices of different shapes and volumes of up to $20 \mathrm{~cm}^{3}$ and silicon with a definite weight ratio, $\psi=\mathrm{Si} / \mathrm{C}$, which was varied in the range from 2.0 to 4.0 , were added to individual crucibles. The ratio $\psi$ was determined by weighing the carbon matrix and silicon powder before the impregnation/syntheses process. The crucibles were produced by completely immersing the matrices into a silicon melt. We used the FIP for a Si melt. This consists of forced suction of liquid silicon in the porous matrix. ${ }^{13}$ Liquid silicon penetrates through the pores into the matrix at melting. The reaction of the synthesis can be described as follows:

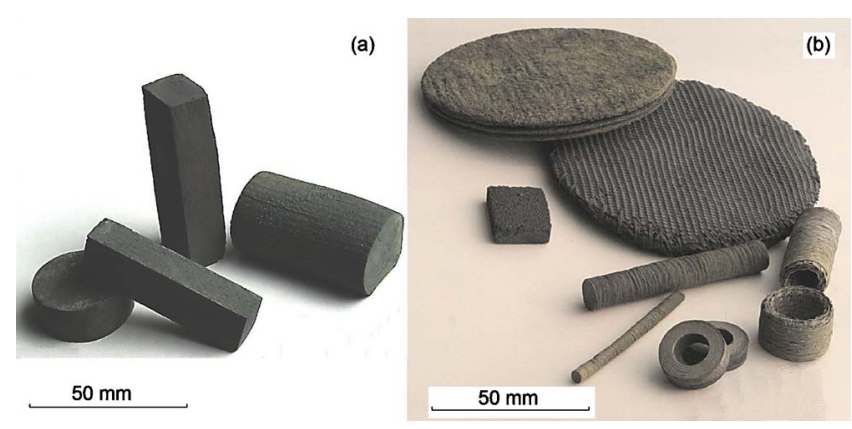

FIG. 1. (Color online) Typical ceramic samples obtained using the FIP from carbon matrices of (a) natural wood and, for comparison, (b) produced by industry.

$$
\mathrm{C}_{\mathrm{sol}}+\mathrm{Si}_{\text {liq }} \rightarrow \mathrm{SiC}_{\mathrm{sol}} \text {. }
$$

The process has two stages. The aim of these stages is the impregnation of carbon matrices by silicon and syntheses of the $\mathrm{SiC}$. The first stage was realized under variable pressure of $\mathrm{He}$ within the temperature range of $\mathrm{T}=1450-1600{ }^{\circ} \mathrm{C}$ and duration $t_{s}=10-20$ min. ${ }^{13}$ The goal of the second stage is the evaporation of excess silicon so that this stage was fulfilled in vacuum, slowly increasing the temperature at a rate of $10-20{ }^{\circ} \mathrm{C} / \mathrm{min}$ up to $\mathrm{T}_{\max }=1800-2100{ }^{\circ} \mathrm{C}$. The duration of the second stage was in the range of $t_{e v}$ $=30-90 \mathrm{~min}$. The total duration of the processes of impregnation/synthesis and evaporation, $\mathrm{t}_{\Sigma}$, was estimated from the beginning of the silicon melting process at $\mathrm{T}$ $=1420{ }^{\circ} \mathrm{C}$ to the moment of the achievement of $\mathrm{T}_{\max }$, followed by interruption of the heating. If required, excess carbon from the final products was burn out in the furnace in an oxygen atmosphere at $\mathrm{T}=900{ }^{\circ} \mathrm{C}$ for $2 \mathrm{~h}$.

The structure and composition of the materials obtained were investigated using different techniques such as optical microscopy, scanning electron microscopy (SEM), and Raman spectroscopy (RS), and the geometrical density was defined by measuring volume specimens and weighing the samples.

\section{RESULTS AND DISCUSSION}

Typical samples of porous $\mathrm{SiC}$ ceramics produced from a number of carbon matrices are shown in Fig. 1. The digital photographic images of the samples obtained from different wood species demonstrate a variety of microporous structures (Fig. 2). The samples were fabricated under the same conditions. The size of the pores can be defined from a computer analysis of digital photographic images. Data of pore distributions in the size dimensions shown in Fig. 2(f) are calculated by counting the number of pores whose sizes are included in a bin of $5 \mu \mathrm{m}$. The ceramics from hardwood matrices (dicotyledonous angiosperms) with diffusive porous patterns demonstrate good homogeneity of the surface distribution of the pores [Figs. 2(a)-2(e)]. The results are very promising for the development of ceramic materials with sufficiently uniform characteristics. We obtained different functions of pore-size distribution, which define the physical properties of the obtained ceramic material as a function of the carbon matrix. For comparison, in Figs. 2(g) and 2(h) photographic images are shown of the ceramics, produced 


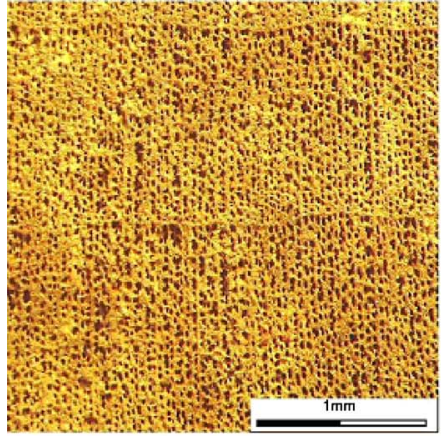

(a)

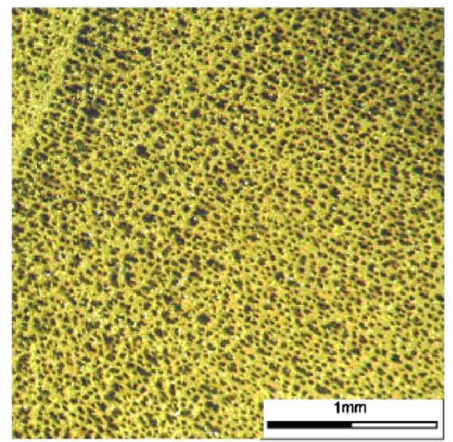

(d)

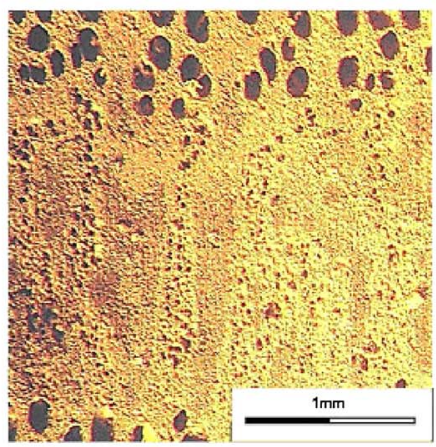

(g)

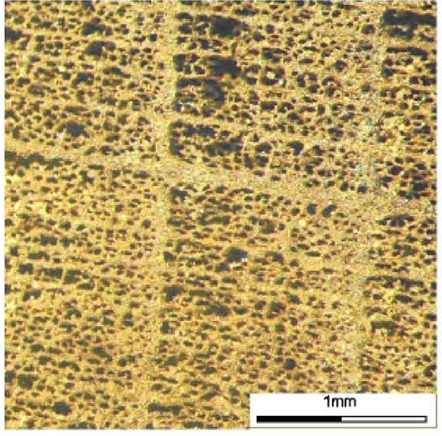

(b)

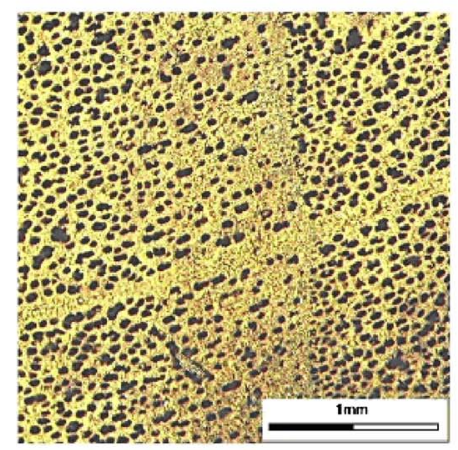

(e)

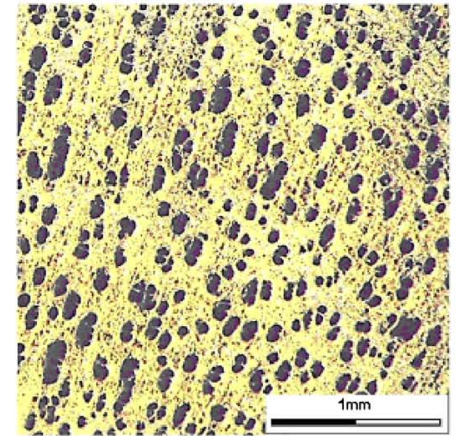

(c)

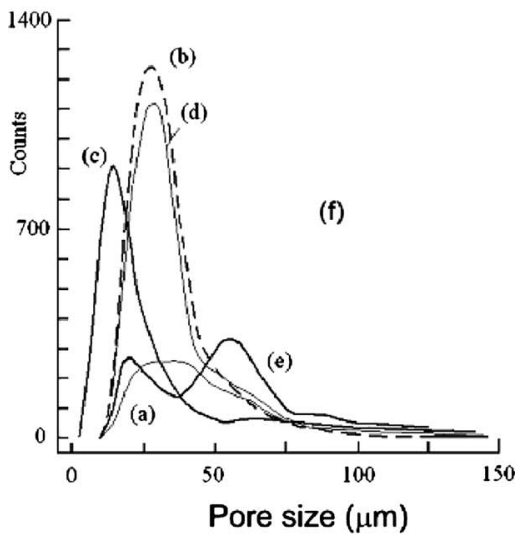

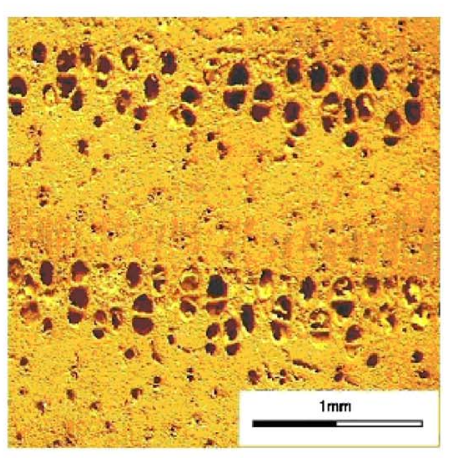

(h)

FIG. 2. (Color online) Optical images of SiC/Si ceramics produced by the FIP from different natural wood species: (a) Persian walnut, (b) beech, (c) European hornbeam, (d) pear tree, (e) alder, (f) pore size distribution, counted as number of the pore sizes included in a bin of $5 \mu \mathrm{m}$, (g) ash tree, (h) oak.

from wood with ring porous patterns. It can be seen that the ceramics show significant inhomogeneous distribution of the pores.

It is known that the optimum correlation of the mass of silicon and the mass of carbon matrices for $100 \%$ conversions in carbide silicon is defined by the chemical formula of $\mathrm{SiC}$ and molecular weight $\mathrm{Si}(28 \mathrm{~g} / \mathrm{mol})$ and $\mathrm{C}(12 \mathrm{~g} / \mathrm{mol})$. Therefore, for $100 \%$ conversion efficiency, the weight balance should be equal to $\psi=2.33$. In the real situation during the ceramic production process part of $\mathrm{Si}$ is lost due to evaporation, or can be absorbed by the walls of the carbon crucible, or cannot be impregnated by the matrix and, as a result, does not participate in the reaction processes. Thus, measurement of the value of the geometric density, $\rho_{\text {cer }}$, or weight, $\mathrm{P}_{\text {cer }}$, of the ceramics (and carbon matrix $\rho_{\text {carb }}, \mathrm{P}_{\text {carb }}$, respectively) before and after impregnation permits an estimate of the efficiency of the method as well as the phase composition of ceramics and the contents of silicon and/or carbon. It should be noted that the maximum permissible quantity of silicon that would entirely fill all the pores in the matrix is determined by the volume of pores. Porosity of carbon matrices depends on the type of wood, and the value $\psi=2.33$ indicates the fact that the weight ratio is stoichiometric although this does not guarantee complete conversion into $\mathrm{SiC}$.

The weight of the ceramics and density after impregnation can be described as:

$$
\mathrm{P}_{\text {cer }}=\mathrm{P}_{\text {carb }}(1+\psi), \quad \rho_{\text {cer }}=\rho_{\text {carb }}(1+\psi) .
$$

If $\mathrm{P}_{\text {cer }} / \mathrm{P}_{\text {carb }}<3.33$, the $\mathrm{SiC} / \mathrm{C}$ composite is formed, and under the relation $\mathrm{P}_{\text {cer }} / \mathrm{P}_{\text {carb }}>3.33$ - the $\mathrm{SiC} / \mathrm{Si}$ composite, respectively. It should be emphasized that the maximum possible amount of silicon cannot exceed the volume of the pores in the carbon matrix. Thus, the estimations show that in the case of the carbon matrix derived from wood $\psi$ should not exceed four. The results of the measurements of the den- 


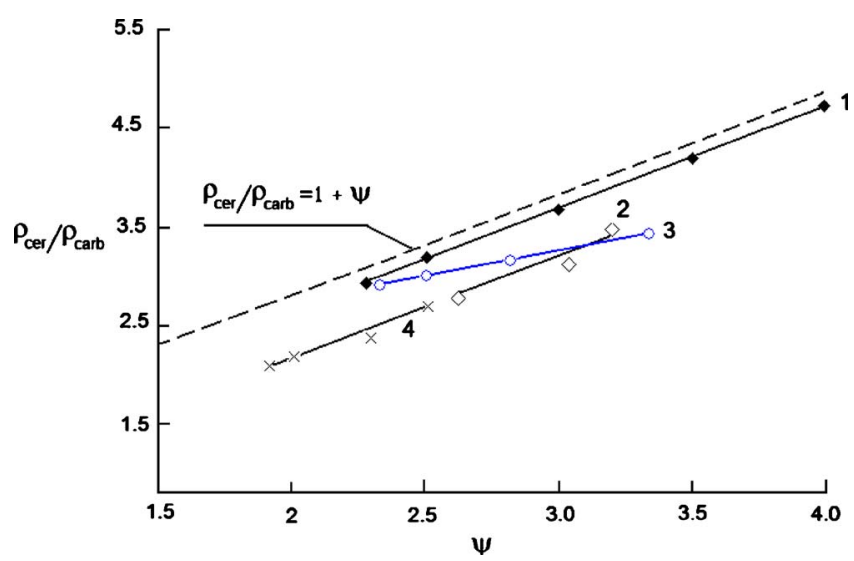

FIG. 3. (Color online) Dependence of density of $\mathrm{SiC}$ ceramics vs weight ratio, $\psi$ : 1-carbon matrices from pear tree $(1$ stage $-\mathrm{t}=15 \mathrm{~min}, \mathrm{~T}$ $=1600{ }^{\circ} \mathrm{C}, 2$ stages- 0 ); 2 -carbon matrices from pear tree (1 stage- $\mathrm{t}$ $=15 \min , \mathrm{T}=1700{ }^{\circ} \mathrm{C}, 2$ stages $-\mathrm{t}=60 \min , \mathrm{T}_{\max }=2100{ }^{\circ} \mathrm{C}$ ); 3-carbon matrices from alder $\left(1\right.$ stage $-\mathrm{t}=15 \mathrm{~min}, \mathrm{~T}=1700{ }^{\circ} \mathrm{C}, 2$ stages $-\mathrm{t}=60 \mathrm{~min}$, $\mathrm{T}_{\max }=2100^{\circ} \mathrm{C}$ ); 4-carbon matrices from Persian walnut (1 stage- $\mathrm{t}$ $=15 \min , \mathrm{T}=1700{ }^{\circ} \mathrm{C}, 2$ stages $-\mathrm{t}=80 \min , \mathrm{T}_{\max }=2100{ }^{\circ} \mathrm{C}$ ).

sity of the samples as a function of weight ratio are shown in Fig. 3. It can be seen that if the evaporation stage is omitted the experimental points deviate slightly from the lines described by $\rho_{\text {cer }} / \rho_{\text {carb }}=(1+\psi)$. This is indicative of the high efficiency of the impregnation method. If the evaporation stage is used even at a temperature of $2100{ }^{\circ} \mathrm{C}$ the content of excess silicon in the ceramics is reduced, although it cannot be completely removed. The evaporation of excess silicon starts from the surface layers only. Thus, the influence of the process of evaporation on the weight of the samples depends on their geometric sizes and, probably, the sizes of the pores. The efficiency of the method can be estimated from the silicon loss after the impregnation process:

$$
\gamma=\left[\mathrm{P}_{\mathrm{carb}}(1+\psi)-\mathrm{P}_{\mathrm{cer}}\right] / \mathrm{P}_{\mathrm{cer},} \%
$$

If a one-stage process was used then the loss of $\mathrm{Si}$ did not exceed 3\%-5\%. If an additional evaporation stage was used then, depending on the temperature and duration of evaporation, the loss may be as high as 30\%-40\%.

In Table I, the data of the geometric density of the carbon matrix and possible range of the change in geometric density corresponding to ceramics under $\psi=2.33$ are summa-
TABLE I. Characteristics of porous $\mathrm{SiC}$ ceramics produced from wood precursors.

\begin{tabular}{lcc}
\hline \hline Wood precursor & $\begin{array}{c}\rho_{\text {carb }} \\
\left(\mathrm{g} / \mathrm{cm}^{3}\right)\end{array}$ & $\begin{array}{c}\rho_{\text {cer }} \\
\left(\mathrm{g} / \mathrm{cm}^{3}\right)\end{array}$ \\
\hline European hornbeam & $0.63-0.65$ & $2.09-2.16$ \\
Beech & $0.45-0.55$ & $1.49-1.83$ \\
Pear tree & $0.43-0.50$ & $1.43-1.66$ \\
Persian walnut & $0.44-0.49$ & $1.46-1.63$ \\
Alder & $0.37-0.39$ & $1.23-1.29$ \\
\hline \hline
\end{tabular}

rized. Obviously, in the case of formation of $\mathrm{SiC} / \mathrm{Si}$ composite the weight of the ceramic density increases with the content of excess silicon.

Vickers hardness $(\mathrm{VH})$ measurements were performed at load $0.1 \mathrm{kN}$. Two orientations were used: parallel and perpendicular to the growth direction of the wood. Three different sets of indentations were studied in both directions due to the inhomogeneity of the materials. It should be noted that sample hardness in the perpendicular direction is two to three times less than in parallel to the direction of growth. The results of hardness versus geometrical density and porosity are shown in Fig. 4. Hardness data demonstrate sufficiently large scattering, which can be explained by taking into account the fact that the geometric density is an integral feature of the material but the results of the measurements depend on the porosity of the ceramic structure in the vicinity of the point of indentation. It can be clearly seen that the hardness increases with geometrical density and decreases with porosity. The increasing density of the $\mathrm{SiC} / \mathrm{Si}$ composite is the result of excess silicon. Silicon fills part of the pores thus reducing the porosity of the ceramics.

It is known that the mechanical characteristics of porous ceramics depend on the porosity. Hardness in porous materials is usually described using an equation of the Ryshkewitch type ${ }^{16}$

$$
\mathrm{VH}=\mathrm{V}_{\mathrm{o}} \mathrm{H} \exp \left(-B \mathrm{~V}_{\mathrm{p}}\right)
$$

where $\mathrm{V}_{\mathrm{o}} \mathrm{H}=27.7 \mathrm{GPa}$ is the hardness of the dense material, a $\mathrm{VH}$ is the hardness of the porous material. B-is a constant depending on the shape of the pore. ${ }^{17,18}$ The fit of the hardness results using this equation gives us $\mathrm{B} \sim 3$ for ceramics
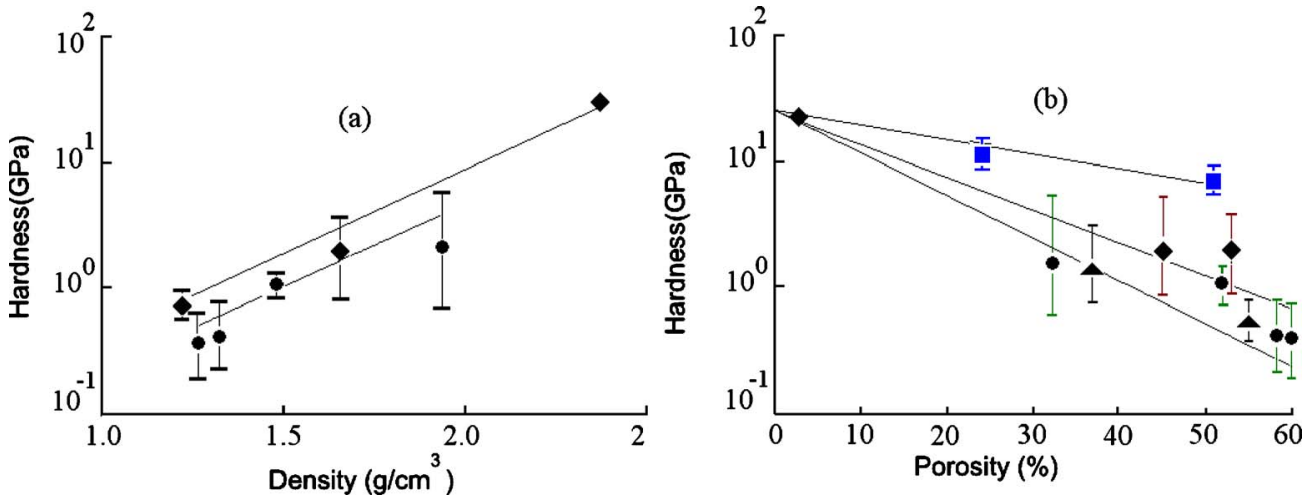

FIG. 4. (Color online) Hardness results measured as a function of geometrical density (a) and (b) porosity -alder, - pear tree, 


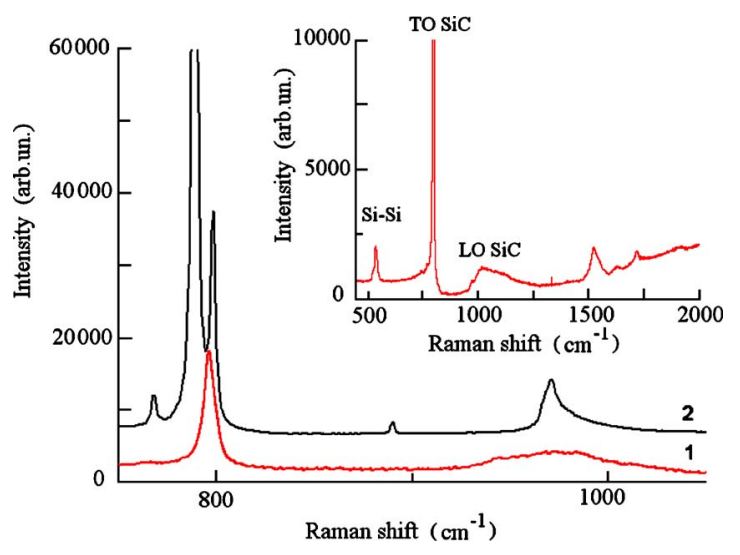

FIG. 5. (Color online) Raman spectra of biomorphic SiC ceramics: (1) synthesized from pear tree at $\mathrm{T}=1600{ }^{\circ} \mathrm{C}(3 \mathrm{C}-\mathrm{SiC})$; (2) synthesized from European hornbeam at $\mathrm{T}=2100{ }^{\circ} \mathrm{C}(6 \mathrm{H}-\mathrm{SiC})$. Inset: wide-range Raman spectrum of biomorphic $\mathrm{SiC}$ ceramics, where $\mathrm{Si}-\mathrm{Si}$ vibrations of nonreacted silicon component are registered.

from European hornbeam and $B=6-7$ for ceramics from beech, alder, and pear trees.

Biomorphic $\mathrm{SiC}$ ceramics can be amorphous or crystalline $^{14}$ and may have different polytypes depending on the technological factors of synthesis. In addition, the ceramics may contain residual carbon and Si clusters, which have not been transformed into $\mathrm{SiC}$ during infiltration in bio-SiC structures. To investigate the phase and polytypes of $\mathrm{SiC}$ ceramics, Raman spectra were measured in backscattering geometry at room temperature. The polarization of both incident as well as registered light was unspecified. The 514.5-nm wavelength of an $\mathrm{Ar}^{+}$laser was used for excitation of the sample with a laser beam directed parallel or perpendicular to the pore lattice. Raman spectra measured for the case of parallel geometry for biomorphic $\mathrm{SiC}(\psi=2.33)$ are shown in Fig. 5. For perpendicular geometry, the spectra obtained are practically the same with the sole exception of a slight shift $\left(\sim 1 \mathrm{~cm}^{-1}\right)$ of TO $\mathrm{SiC}$ mode toward high frequency due to anisotropy of mechanical strains in $\mathrm{SiC}$ ceramics. $\mathrm{SiC}$ structure investigations using $\mathrm{RS}$ allowed us to establish that a synthesis temperature $\sim 1600{ }^{\circ} \mathrm{C}$ results in a $3 \mathrm{C}-\mathrm{SiC}$ polytype formation (Fig. 5, curve 1). Increasing the synthesis temperature plays a crucial role and leads to $3 \mathrm{C}$ as well as $6 \mathrm{H} \mathrm{SiC}$ formation. A further temperature rise results in a higher $6 \mathrm{H}-\mathrm{SiC}$ polytype ratio (Fig. 5, curve 2).

As a rule, the ceramics [Fig. 6(a)] consist of faceted microcrystals of $\mathrm{SiC}$ (size 4-5 $\mu \mathrm{m}$ ). However, increasing the $t_{\Sigma}$ value up to $160 \mathrm{~min}$ at a high temperature $\left(\mathrm{T}_{\max }\right.$ $=2100{ }^{\circ} \mathrm{C}$ ) often caused macrocrystal formation with a size of $150-350 \mu \mathrm{m}$. The polished surface of this sample is shown in Fig. 6(b). It should be noted that such samples have high $\mathrm{VH}, \mathrm{VH}=27 \mathrm{GPa}$. The value is about the same as the hardness of bulk crystals.

The technique developed for growing carbon materials allows the production of ceramics with different shapes and properties Fig. 1(b). Mechanical parameters (density, porosity, hardness) of $\mathrm{SiC}$ ceramic samples are entirely determined by the properties of the initial carbon matrices and can vary over a wide range. The characteristics of porous $\mathrm{SiC}$ ceramics obtained from industrial carbon materials are summarized

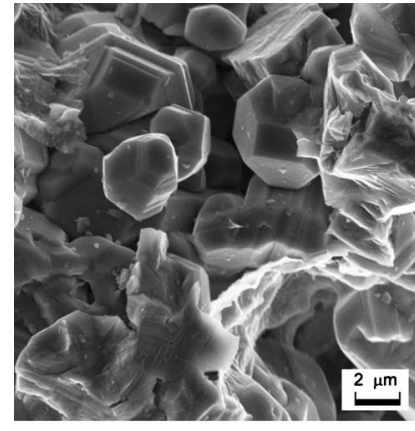

(a)

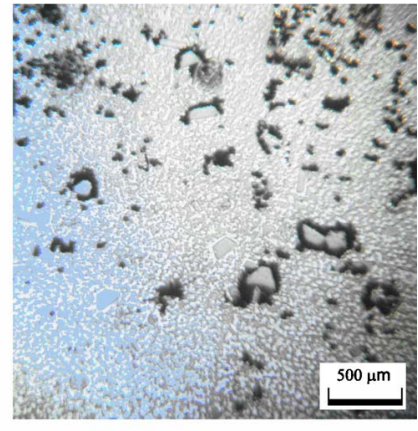

(b)
FIG. 6. (Color online) (a) SEM image of surface of the biomorphous SiC ceramics, (b) microphotography of the pear tree $\mathrm{SiC}$ ceramics produced at $\mathrm{t}_{\Sigma}=160 \mathrm{~min}, \mathrm{~T}_{\max }=2100^{\circ} \mathrm{C}$.

in Table II. In this case, a one-stage process was used ( $\mathrm{t}$ $=15 \mathrm{~min}, \mathrm{~T}=1700{ }^{\circ} \mathrm{C}$ ) for the ceramic production.

\section{CONCLUSION}

A FIP of porous carbon matrices by liquid $\mathrm{Si}$ was developed. The matrices were prepared using natural hardwoods (dicotyledonous angiosperms) as well as different industrial carbon materials, including carbon fibers, carbon foil, fibers, filaments, fabric, felt, carbon foam, and combinations of these. It is shown that by using hardwoods (dicotyledonous angiosperms) carbon matrices with diffusive porous patterns can be used for the production of ceramics with homogeneous characteristics. In addition, this technology allows the matrices to be impregnated with a wide range of pore sizes such as: from several microns up to several millimeters (carbon fabric).

The silicon impregnation process and $\mathrm{SiC}$ synthesis were studied in a wide temperature range of $1700-2100{ }^{\circ} \mathrm{C}$. It was found that the phase composition is defined by relation between the weight of silicon and carbon $\psi=\mathrm{Si} / \mathrm{C}$. It is shown that the evaporation stage, even at a temperature of $2100{ }^{\circ} \mathrm{C}$, results in a reduction in the contents of excess silicon in ceramics, but does not completely remove the silicon. Thus, in the case of the forced impregnation method the value $\psi=\mathrm{Si} / \mathrm{C}$, the phase composition of the ceramics as well as the $\mathrm{SiC} / \mathrm{C}$ or $\mathrm{SiC} / \mathrm{Si}$ composite material produced can be safely controlled. Definite polytypes of the resulting biomorphic $\mathrm{SiC}$ ceramics can be managed depending on the technological factors of the synthesis. At temperature $\mathrm{T}$ $<1700{ }^{\circ} \mathrm{C}$ the ceramic has a $3 \mathrm{C}-\mathrm{SiC}$ polytype while at increasing temperature $\mathrm{T}>1800{ }^{\circ} \mathrm{C}$ it shows the appearance of $6 \mathrm{H}-\mathrm{SiC}$ polytype. In addition, if the temperature is increased to $\mathrm{T}=2100{ }^{\circ} \mathrm{C}$ and with a long duration of the syn-

TABLE II. Characteristics of porous $\mathrm{SiC}$ ceramics from industrially produced carbon materials.

\begin{tabular}{lcc}
\hline \hline Starting materials & $\begin{array}{c}\rho_{\text {cer }} \\
\left(\mathrm{g} / \mathrm{cm}^{3}\right)\end{array}$ & Major phases \\
\hline Carbon fibers & $2.0-2.6$ & $\beta-\mathrm{SiC} / \mathrm{Si}$ \\
Carbon felt & $0.4-0.7$ & $\beta-\mathrm{SiC} / \mathrm{Si}$ \\
Carbon foam & $0.18-0.21$ & $\beta-\mathrm{SiC} / \mathrm{Si} / \mathrm{C}$ \\
\hline \hline
\end{tabular}


thesis process, $\alpha$-SiC macrocrystals may be formed. Experimental results of $\mathrm{VH}$ demonstrate that the hardness increases with the geometrical density and decreases with porosity. Hardness in porous $\mathrm{SiC}$ materials is well described using an equation of the Ryshkewitch type.

Thus, $\mathrm{SiC}$ ceramics of various porosities, compositions and, consequently, various physical properties can be successfully synthesized, which is promising for a broad range of practical applications.

${ }^{1}$ F. M. Varela-Feria, J. Martínez-Fernández, A. R. de Arellano-López, and M. Singh, J. Eur. Ceram. Soc. 22, 2719 (2002).

${ }^{2}$ P. Greil, J. Eur. Ceram. Soc. 21, 105 (2001)

${ }^{3}$ A. Bolz, M. Amon, C. Ozbek, B. Heublein, and M. Schaldach, Tex Heart Inst. J. 23, 162 (1996).

${ }^{4}$ S. H. Monnink, A. J. van Boven, H. O. Peels, I. Tigchelaar, P. J. de Kam, H. J. Crijns, and W. van Oeveren, J. Investig. Med. 47, 304 (1999).

${ }^{5}$ S. Santavirta, M. Takagi, L. Nordsletten, A. Anttila, R. Lappalainen, and Y. T. Konttinen, Arch. Orthop. Trauma Surg. 118, 89 (1998).

${ }^{6}$ P. Gonzalez, J. Serra, S. Liste, S. Chiussi, B. Leon, M. Perez-Amor, J. Martinez-Fernandez, A. R. de Arellano-Lopez, and F. M. Varela-Feria,
Biomaterials 24, 4827 (2003).

${ }^{7}$ P. Gonzalez, J. P. Borrajo, J. Serra, S. Chiussi, B. Leon, J. MartinezFernandez, F. M. Varela-Feria, A. R. de Arellano-Lopez, A. de Carlos, F. M. Munoz, M. Lopez, and M. Singh, J. Biomed. Mater. Res. 88A, 807 (2009).

${ }^{8}$ A. Rosenbloom, D. Sipe, Y. Shishkin, Y. Ke, R. P. Devaty, and W. J. Choyke, Biomed. Microdevices 6, 261 (2004).

${ }^{9}$ K.-H. Thiermann and W. Schafer, CFI, Ceram. Forum Int. 80, E15 (2000).

${ }^{10}$ An Introduction to Bioceramics, edited by L. L. Hench and J. Wilson (World Scientific, Singapore, 1993).

${ }^{11}$ P. Greil, T. Lifka, and A. Kaindl, J. Eur. Ceram. Soc. 18, 1961 (1998).

${ }^{12}$ X. Zhu, D. Jiang, and S. Tan, Mater. Sci. Eng., A 323, 232 (2002).

${ }^{13}$ A. E. Belyaev and V. S. Kiselov, Ukrainian Patent No. 87187, (25 June 2009).

${ }^{14}$ V. S. Kiselov, E. N. Kalabukhova, A. A. Sitnikov, P. M. Lytvyn, V. I. Poludin, V. A. Yukhymchyk, and A. E. Belyaev, Semicond. Phys., Quantum Electron. Optoelectron. 12, 68 (2009).

${ }^{15}$ V. I. Poludin, M. P. Kiselyuk, T. A. Kryskov, and A. E. Belyaev, Semicond. Phys., Quantum Electron. Optoelectron. 12, 64 (2009).

${ }^{16}$ E. Ryshkewitch, J. Am. Ceram. Soc. 36, 65 (1953).

${ }^{17}$ J. Gibson and M. F. Ashby, Cellular Solids: Structure and Properties (Cambridge University Press, Cambridge, 1999).

${ }^{18}$ R. W. Rice, J. Mater. Sci. 31, 102 (1996). 